\title{
How to Improve Information Technology to Support Healthcare to Address the COVID-19 Pandemic: an International Survey with Health Informatics Experts
}

\author{
Max Topaz (first co-author)' ${ }^{1}$ Laura-Maria Peltonen (first co-author) ${ }^{2}$, James Mitchell ${ }^{3}$, Dari \\ Alhuwail ${ }^{4,5}$, Seyedeh-Samin Barakati ${ }^{6}$, Adrienne Lewis ${ }^{7}$, Hans Moen ${ }^{8}$, Sai Pavan Kumar \\ Veeranki ${ }^{9},{ }^{10}$, Lori Block ${ }^{11}$, Tracie Risling ${ }^{12}$, Charlene Ronquillo, ${ }^{6,11}$ \\ 1 School of Nursing, Columbia University, New York, USA \\ 2 Department of Nursing Science, University of Turku, Finland \\ 3 School of Computing and Mathematics, Keele University, UK \\ 4 Information Science Department, Kuwait University, Kuwait \\ 5 Health Informatics Unit, Dasman Diabetes Institute, Kuwait \\ 6 Daphne Cockwell School of Nursing, Ryerson University, Toronto, Canada \\ 7 Splatsin Health Services, Enderby, BC, Canada \\ 8 Department of Future Technologies, University of Turku, Finland \\ 9 Health \& Bioresources / Molecular Diagnostics, AIT Austrian Institute of Technology GmbH, Graz, \\ Austria \\ ${ }^{10}$ Technical University of Graz, Graz, Austria \\ "School of Nursing, University of British Columbia Vancouver, BC, Canada \\ ${ }^{12}$ College of Nursing, University of Saskatchewan, Saskatoon, SK, Canada
}

\section{Summary}

Objectives: To identify the ways in which healthcare information and communication technologies can be improved to address the challenges raised by the COVID-19 pandemic. Methods: The study population included health informatics experts who had been involved with the planning, development and deployment of healthcare information and communication technologies in healthcare settings in response to the challenges presented by the COVID-19 pandemic. Data were collected via an online survey. A non-probability convenience sampling strategy was employed. Data were analyzed with content analysis.

Results: A total of 65 participants from 16 countries responded to the conducted survey. The four major themes regarding recommended improvements identified from the content analysis included: improved technology availability, improved interoperability, intuitive user interfaces and adoption of standards of care. Respondents also identified several key healthcare information and communication technologies that can help to provide better healthcare to patients during the COVID-19 pandemic, including telehealth, advanced software, electronic health records, remote work technologies (e.g., remote desktop computer access), and clinical decision support tools. Conclusions: Our results help to identify several important healthcare information and communication technologies, recommended by health informatics experts, which can help to provide better care to patients during the COVID-19 pandemic. The results also highlight the need for improved interoperability, intuitive user interfaces and advocating the adoption of standards of care.

\section{Keywords}

Health Informatics, COVID-19, international survey, telehealth

Yearb Med Inform 2021:61-8

http://dx.doi.org/10.1055/s-0041-1726491

\section{Introduction and Objectives}

The coronavirus (SARS-CoV-2) pandemic has challenged the healthcare sector globally in several ways. The pandemic has worsened the shortage of the healthcare workforce $[1,2]$ and increased the workload [3] and psychosocial burden of health professionals [4-6]. Healthcare providers have reorganized resources to manage the increased demands of care [7]. However, shortages in medical equipment, [8-10] personal protective equipment, [2, 8-12] and healthcare information technologies further challenged the response to the COVID-19 pandemic [13, 14].

Advanced technological solutions that can reduce the burden of limited health care resources perpetuated by this pandemic are necessary [15]. Globally, the application of 
healthcare information and communication technologies varies with respect to countries' economic status and the expenditure on these technologies corresponding to their national budgets. Nonetheless, the COVID-19 pandemic has boosted the rate of technology adoption, particularly, related to digital health services $[16,17]$. Multiple technology tools have rapidly been adopted to assist in the struggle against the pandemic. Examples include tools for case identification [18], contact tracing [19], mobility data communication [20], robotic disinfection [21] among many others.

On the one hand, physical distancing has become a key strategy in containing the spread of the virus, and on the other hand, technologies such as chatbots and virtual care technologies have filled the gap in providing healthcare services previously done face to face $[22,23]$. Artificial intelligence has also been identified as one of the key technologies used during the pandemic. For example, it has been used in the detection of COVID-19 cases, diagnosis, monitoring vital parameters, contact tracing, prediction of virus spread, treatment suggestions as well as vaccine development [22-24]. However, the applied use and research on interoperability standards, like FHIR [25], OpenEHR [26], and SNOMED-CT [27], and telehealth technologies (including the Internet of Things), to succor the COVID-19 pandemic, have received less attention [28]. Further, the application and usability of these technologies on patient safety are yet to be fully understood in this pandemic context [29, 30].

There is a need to reflect on the use of healthcare information and communication technologies during the COVID-19 pandemic to find ways to better support health systems during pandemics. The International Medical Informatics Association (IMIA) Students and Emerging Professionals Special Interest Group conducted an international survey targeted at health informatics experts. As there is a large variation in application of healthcare information and communication technologies throughout the globe [31], we purposefully sought perspectives from an international cohort of health informatics experts. The survey can be accessed via http://covidhitimpact.com.
This study aimed to identify the ways in which healthcare information and communication technologies can be improved to address challenges raised by the COVID-19 pandemic.

\section{Methods}

The study had a descriptive exploratory design and data were collected via an online survey. The population was international health informatics experts who have been involved with the planning, development and deployment of health information technology in healthcare settings in response to challenges presented by the COVID-19 pandemic. The data collection time considered responses from March to May 2020. A non-probability convenience sampling method, where the population cannot be identified [32] was employed given the exploratory nature of the survey and the aim, which was to be as wide-reaching as possible. This method allowed the research team to select samples based on selective judgement, rather than by random selection [32]. As such, it was not possible to predetermine a specified sampling frame. An invite to participate in the study was sent out through the IMIA Students and Emerging Professionals Special Interest Group networks (including the group's mailing list, professional networks, other relevant mailing lists, social media, word of mouth, and snowball sampling [33]).

The web-based survey was developed and advertised as per best practices on Web survey design as outlined in the Tailored Design Method [34, 35]. This included consultation with health informatics experts as part of survey development, to assure adequate functionality, clarity and content validity prior to distribution. Recognizing that our target sample group was health informatics experts who were working under immense pressures, a very brief, open-ended survey was developed to maximize the likelihood of response. The survey consists of 10 open-ended questions that covered the nature of health information and communication technologies used and implemented in healthcare settings in relation to or as part of the pandemic response. The online survey used the Opinio ${ }^{\mathrm{TM}}$ software provided by Ryerson University with servers located in Canada. Ethical approval was obtained from Ryerson University Research Ethics Board (REB 2020-175), Kuwait University (KU-CLS-20-05-13) and the University of Keele (ECL270420).

This paper reports the responses to the question "What technologies do you wish you had to help address COVID-19 in your setting?" Initially, the study team considered providing a structured checklist option of selected technologies to the question mentioned above. In this case, study participants would have been expected to select several specific technologies from a dropdown list. However, no such comprehensive list of technologies was available and we designed an open ended question that would provide study participants the freedom to respond to the question in a non-restrictive manner [36].

We implemented qualitative thematic content analysis to analyze the responses [37]. Specifically, two $\mathrm{PhDs}$ prepared reviewers (LMP and MT), with backgrounds in health informatics and experience in thematic content analysis, independently reviewed each of the study responses. The researchers assigned the responses with a set of preliminary and emerging themes. As each individual response could contain several technologies, it was possible that several themes were coded for one response (e.g., "better user interfaces" and "improved technology availability"). The candidate list of themes was then discussed and finalized with the broader study team (LMP, MT, S-SB, CR). Specifically, the assigned emerging themes were discussed, harmonized, assigned a consistent name and agreed on by both reviewers and the study team. This resulted in a final list of major themes and several specific sub-themes. These major themes are presented with their number of mentions in the collected data.

\section{Results}

A total of 65 participants from 16 countries responded to the survey. Most of the study participants identified their current professional role as applied clinical informatician or informaticist $(42 \%, n=27)$ and many 
respondents were from Canada $(43 \%, \mathrm{n}=28)$. The majority reported working in a hospital setting or a large healthcare facility $(60 \%$, $\mathrm{n}=35$ ). The primary role, setting in which the participants worked, and the countries of respondents are outlined in Table 1.

Responses were coded with 87 initial codes that were related to desired improvements to technologies during the COVID-19 pandemic. Three respondents from Canada (IDs 34, 39 and 45) and two from the UK (IDs 4 and 72) reported already having all the technologies needed to address COVID-19 in their setting. One respondent had no opinion (ID 25) and another responded that technologies needed were "unknown" (ID 30). The remaining 80 initial codes were organized into four major themes through the qualitative thematic analysis. These themes were: improved technology availability, improved interoperability, intuitive user interfaces, and adoption of standards of care. The themes, subthemes and mentions per country are presented in Table 2. The following paragraphs describe each of the themes in more detail.

\subsection{Theme 1: Improved Technology Availability}

Overall, the majority $(68.8 \%, n=55)$ of study participants suggested that additional software and technology might be necessary. Sub-themes of specific suggested technologies included telehealth, advanced software, electronic health records (EHRs), remote work technologies, and clinical decision support tools. Representative quotes for Theme 1 are presented in Table 3. Specific recommendations on technologies included:

- Almost one fourth of the participants suggested advancing telehealth reach and capabilities (Quotes 1.1 and 1.2). Other telehealth suggestions included COVID-19 specific capabilities, such as remote COVID-19 symptom and vital sign monitoring (Quote 1.3). Chatbots were also considered helpful (Quote 1.4);

- Almost one fourth of the participants proposed the development and implementation of advanced software solutions to support in COVID-19 surveillance and contact tracing, as well as in real-time access, collection and analysis (e.g.

Table 1 Role, work setting and countries of respondents.

\begin{tabular}{|c|c|}
\hline Participant Role & Number of respondents \\
\hline Applied clinical informatician/informaticist & 27 \\
\hline $\begin{array}{l}\text { Healthcare professional involved with technology development, } \\
\text { deployment, or evaluation }\end{array}$ & 11 \\
\hline Programmers or developer for a hospital or other health organization & 11 \\
\hline $\begin{array}{l}\text { Administrative roles overseeing technology development, deployment, } \\
\text { or evaluation }\end{array}$ & 10 \\
\hline Healthcare professional currently using health information technologies & 5 \\
\hline No response & 1 \\
\hline Participant Setting & Number of respondents \\
\hline Hospital setting and large healthcare facilities & 35 \\
\hline National IT company & 6 \\
\hline Clinics and smaller health care facilities & 5 \\
\hline Regional health organization & 4 \\
\hline Ministry of Health & 4 \\
\hline University & 2 \\
\hline Pharmaceutical & 2 \\
\hline Other & 7 \\
\hline Country & Number of respondents \\
\hline Canada & 28 \\
\hline UK & 11 \\
\hline Spain & 7 \\
\hline Finland & 4 \\
\hline USA & 2 \\
\hline Qatar & 2 \\
\hline Kuwait & 2 \\
\hline Australia & 1 \\
\hline Central and West Africa & 1 \\
\hline Germany & 1 \\
\hline Jordan & 1 \\
\hline Nigeria & 1 \\
\hline Norway & 1 \\
\hline Oman & 1 \\
\hline Switzerland & 1 \\
\hline Taiwan & 1 \\
\hline
\end{tabular}

dashboards) of information on local and national levels (Quotes 1.5 and 1.6);

- Another common suggested technology was the $\boldsymbol{E H R}$. Some participants reported that clinical documentation in their settings was still mainly done on paper (Quote 1.7). Other participants wished for higher quality EHRs that support documentation and care

- Remote work technologies were also encouraged by study participants (Quotes 1.8 and 1.9). Specifically, respondents suggested remote technologies included virtual private networks (VPN) and remote desktop access technologies, like Citrix; 
Table 2 Desired improvements to technologies during COVID-19 pandemic by themes, subthemes and mentions per country

\begin{tabular}{|c|c|c|c|}
\hline Major theme & Sub-theme & \# mentions per country & $\%$ participants \\
\hline \multirow[t]{38}{*}{ Improved technology availability } & & 55 & $68.8 \%$ \\
\hline & Telehealth & Canada: 6 & \\
\hline & & Finland: 4 & \\
\hline & & Spain: 3 & \\
\hline & & Australia: 1 & \\
\hline & & Jordan: 1 & $23.8 \%$ \\
\hline & & Kuwait: 1 & \\
\hline & & Norway: 1 & \\
\hline & & UK: 1 & \\
\hline & & USA: 1 & \\
\hline & & Total: 19 & \\
\hline & Advanced software & Canada: 5 & \\
\hline & & UK: 4 & \\
\hline & & Finland: 2 & \\
\hline & & Oman: 2 & \\
\hline & & Central and West Africa: 1 & \\
\hline & & Norway: 1 & $22.5 \%$ \\
\hline & & Qatar: 1 & \\
\hline & & Spain: 1 & \\
\hline & & Taiwan: 1 & \\
\hline & & Total: 18 & \\
\hline & Electronic health records & Canada: 4 & \\
\hline & & Kuwait: 1 & \\
\hline & & Nigeria: 1 & $8.8 \%$ \\
\hline & & Spain: 1 & \\
\hline & & Total: 7 & \\
\hline & Remote work technology & Canada: 2 & \\
\hline & (e.g., VPN) & Germany: 1 & \\
\hline & & Kuwait: 1 & \\
\hline & & Spain: 1 & $7.5 \%$ \\
\hline & & UK: 1 & \\
\hline & & Total: 6 & \\
\hline & Clinical decision support & Canada: 1 & \\
\hline & & Central and West Africa: 1 & \\
\hline & & Germany: 1 & $6.3 \%$ \\
\hline & & Spain: 1 & \\
\hline & & UK: 1 & \\
\hline & & Total: 5 & \\
\hline \multirow[t]{5}{*}{ Improved interoperability } & & Canada: 7 & \\
\hline & & UK: 2 & \\
\hline & & Finland: 1 & $13.8 \%$ \\
\hline & & Switzerland: 1 & \\
\hline & & Total: 11 & \\
\hline \multirow[t]{4}{*}{ Intuitive user interfaces } & & Canada: 5 & \\
\hline & & Finland: 1 & \\
\hline & & UK: 1 & $8.8 \%$ \\
\hline & & Total: 7 & \\
\hline \multirow[t]{4}{*}{ Adoption of standards of care } & & Canada: 5 & $8.8 \%$ \\
\hline & & Nigeria: 1 & \\
\hline & & Qatar: 1 & \\
\hline & & Total: 7 & \\
\hline
\end{tabular}

- In addition, some participants suggested that better clinical decision support tools were needed. Most of the suggested clinical decision support tools focused on COVID-19. For example, several participants indicated the necessity of creating COVID-19 triage clinical decision support (Quotes 1.10 and 1.11).

\subsection{Theme 2: Improved Interoperability}

Another common theme was improved interoperability (reported by $13.8 \%, \mathrm{n}=$ 11). In some cases, the need for improved interoperability was mentioned in the context of one healthcare setting (Quote 2.1). In other cases, interoperability was encouraged between different healthcare settings, including the creation and improvement of national and international information exchanges (Quotes 2.2 to 2.4). Representative quotes for Theme 2 are presented in Table 4.

\subsection{Theme 3: Intuitive User Interfaces}

A need for intuitive user interface was another theme that emerged from the analysis $(8.8 \%, n=7$ of participants). Participants recommended using better designed, more user centered systems, which could be adopted to a wide range of healthcare professionals and disciplines. Representative quotes for Theme 3 are presented in Table 5 (Quotes 3.1 to 3.3).

\subsection{Theme 4: Adoption of Standards of Care}

Lastly, participants advocated for the adoption of standards of care $(8.8 \%, \mathrm{n}=7$ of participants). Some of the suggested standards were general (Quote 4.1), but most were COVID-19 specific. Several participants recommended developing a standardized "COVID-19 case management module" in EHRs (Quotes 4.2-4.3). Representative quotes for Theme 4 are presented in Table 6 . 
Table 3 Representative quotes for theme 1: Improved technology availability

\begin{tabular}{|c|c|}
\hline \# & Quotes for theme 1: Improved technology availability \\
\hline 1.1 & "We should have had video consultations" (Norway, ID 7) \\
\hline 1.2 & "Easy glucose upload technology and easier at home HbAIC kits for remote testing" (UK, ID 57) \\
\hline 1.3 & "... more device integration in the single rooms for vital signs [monitoring]" (Australia, ID 53) \\
\hline 1.4 & "Different kinds of bots/chatbots have turned out to be very efficient" (Finland, ID 83) \\
\hline 1.5 & $\begin{array}{l}\text { "A BI [business intelligence] dashboard that shows cases of the country with integrated databases that enables to view } \\
\text { real time and accurate data of the all facilities in the country. Which helps in faster decision making." (Qatar, ID 31) }\end{array}$ \\
\hline 1.6 & "Data analysis and machine learning, but only when we can get our hands on the relevant data." (UK, ID 77) \\
\hline 1.7 & "Only partial documentation in some areas of the hospital. A lot is paper based." (Canada, ID 42) \\
\hline 1.8 & "More laptops to enable home working" (UK, ID I) \\
\hline 1.9 & ... giving remote access for more workers, not only the head of the team." (Kuwait, ID 20) \\
\hline 1.10 & Better risk stratification tools to identify patients who require clinical care during COVID restrictions" (UK, ID 57) \\
\hline 1.11 & [COVID-19] triage management support" (Central and West Africa, ID 29) \\
\hline
\end{tabular}

Table 4 Representative quotes for theme 2: Improved interoperability

\begin{tabular}{|c|c|}
\hline \# & Quotes for theme 2: Improved interoperability \\
\hline 2.1 & "Systems [in the hospital] where data can be more easily linked by common threads and keys" (UK, ID 6) \\
\hline 2.2 & $\begin{array}{l}\text { "Perhaps a more responsive exchange of information flow between the EHRs at the hospital level and General } \\
\text { Practice Systems" (UK, ID 28) }\end{array}$ \\
\hline 2.3 & "One Provincial information system to enable easy access to information" (Canada, ID 36) \\
\hline 2.4 & $\begin{array}{l}\text { "I wish that the provincial medical health officers, the folks at the WHO, etc. (decision makers) had accurate, } \\
\text { real-time semantically rich and reliable data provided by an interoperable system, rather than having to rely on } \\
\text { models to make these [COVID-19 related] society-transforming decisions." (Canada, ID 50) }\end{array}$ \\
\hline
\end{tabular}

Table 5 Representative quotes for theme 3: Intuitive user interfaces

\begin{tabular}{|ll|}
\hline$\#$ & Quotes for theme 3: Intuitive user interfaces \\
\hline 3.1 & $\begin{array}{l}\text { "Mobile applications and devices that are easy to manage as just another kind of user interface, as the smaller end } \\
\text { of a wide range of options for deploying capabilities to users. Currently, they are still awkward and 'special', with too } \\
\text { much proprietary differentiation and applications tied to specific device manufacturers." (UK, ID 11) }\end{array}$ \\
3.2 & $\begin{array}{l}\text { "[we need] Easily used software, we have a wide range of disciplines at [name of a hospital system], some are tech } \\
\text { champions - some are not" (Canada, ID 56) } \\
3.3 \quad \text { "Better interface and simpler configuration" (Canada, ID 40) }\end{array}$ \\
\hline
\end{tabular}

Table 6 Representative quotes for theme 4: Adoption of standards of care

\begin{tabular}{|ll|}
\hline$\#$ & Quotes for theme 4: Adoption of standards of care \\
\hline 4.1 & "Standard terminologies integrated to our EHR [electronic health record]" (Canada, ID 35) \\
4.2 & "[electronic health record should have standardized] COVID-19 case management module." (Nigeria, ID 71) \\
4.3 & "Development of tool within our EHR [electronic health record] for screening and documentation of COVID-19 related \\
& issues" (Canada, ID 75)
\end{tabular}

\section{Discussion}

The results presented in this paper highlight health informatics experts' suggested technologies as well as characteristics of those technologies to support a better COVID-19 pandemic response at the beginning of the pandemic. These technologies are related to four key themes: improved technology availability, improved interoperability, intuitive user interfaces, and an adoption of standards of care.

The requirement for improved technology availability and functionality were identified as the first theme. Respondents' suggestions of characteristics of existing technologies (EHRs and clinical decision support tools) related to both the desire for specialized functionalities in relation to COVID-19 (e.g., triaging COVID-19 patients based on signs and symptoms), as well as the need to address what are likely longstanding challenges of these technologies with respect to efficiency and quality $[38,39]$. For example, participants reported that the documentation was still largely paper based; the limitations of paper-based documentation was likely made particularly acute given the need for streamlining information to mount an effective pandemic response. In considering these results, it is important to recognize that the pandemic has influenced the development and use of technology differently across settings and countries [40, 41]. This was noted in our sample and reflected in the nature and characteristics of technologies that respondents were hoping for (e.g., basic EHRs versus advanced decision support systems). This indicates large variability of technology maturity not only on national levels but also across the organizations in high-income countries.

Telehealth and remote working tools were identified as key technologies to support health systems' COVID-19 pandemic responses due to the requirements for physical distancing and lockdown measures in many countries [18, 42, 43]. Implementation of digital technologies and incorporating these into health policy is one suggested means for successful information management to adopt crucial strategies as a response to the pandemic, including contact tracing, early surveillance, COVID-19 testing and quar- 
antine [44]. The potential uses of telehealth as indicated by respondents in this study are similar to those found in other studies and include COVID-19 symptom screening and tracking, support for specialized care for hospitalized patients with COVID-19, and providing access to essential healthcare for non-COVID-19 patients [41, 44, 45].

Healthcare interoperability at the local, national, and international levels was also identified as one of the key suggested technologies. Current literature supports this request for interoperability, suggesting that interoperable health data is the missing link for the successful delineation of the COVID-19 pandemic [46-48]. Increased interoperability can help to specify COVID-19 patient population, track symptoms at scale, and potentially contribute to identification of COVID-19 treatments [49].

Our results also highlight the critical need for better technology usability to better support health professionals in this pandemic. The level of user training influences the adoption of healthcare information and communication technologies [31] and usability is one of the most common challenges internationally [50,51]. Studies that have evaluated the usability of technologies used in response to or as key tools during the COVID-19 pandemic highlight the importance of effective user interfaces and easy to use tools, particularly as these can represent important complementary tools to support offline health services (e.g., COVID-19 testing) [52-54]. Results from this study support the need for greater efforts and investment in system usability. In particular, our results point to the importance of accounting for the wide variability of end-users' overall digital literacy and exposure to using specialized technologies, in addition to the differing backgrounds and disciplines of end-users when considering usability. Given the importance and urgency of effectively responding to the pandemic, usability plays an especially crucial role. The time that may have typically been afforded to dedicated training of end-users may not be a possibility in the context of the COVID-19 pandemic, where tools need to be implemented as rapidly as possible.

The final theme identified in this study points to the wish for establishment of health standards to support response to the COVID-19 pandemic, with participants suggesting standardized modules for COVID-19 documentation. Since the time from which responses to this study were collected, documentation standards specific to COVID-19 have been developed [55] as well as forward facing strategies to enable the use of COVID-19 EHR documentation for future research $[56,57]$.

Overall, none of the themes identified in this study regarding technologies, which can be improved to address challenges raised by the COVID-19 pandemic suggested by health informatics experts were surprising. These results nevertheless reflect the degree to which health technologies developments and infrastructures have been catapulted into the spotlight as a result of the pandemic. The themes identified in this study reflect longstanding shortcomings of health informatics infrastructure that have been amplified during the pandemic $[44,48]$. Results of this study reinforce the need to speed up developments in health information technologies and access to those technologies, interoperability, usability, and health standards $[49,58]$.

Future research is needed to explore successful implementation of telehealth services and opportunities for a broader use of remote work technology in the health setting. Research is needed on how to better support the adoption of standards of care with information systems and also to identify possibilities to improve information exchange within the healthcare sector. Research is also needed for the development of a variety of advanced software tools for automated information access and analysis to support decision-makers on different levels in the health setting. These results have high relevance for the health informatics community, with areas for further technology development.

There are two main strengths in our study compared to previous studies. First, we used primary data, which provides empirical evidence for recommendations that other literature outline. Second, our international participant pool can provide a more global perspective as compared to the literature, which mostly consists of systematic review papers or case reports from single institutions. Limitations of this study include the unevenly distributed sample with a majority of respondents from North America. Other limitations include a lack of description of technologies used by the participants, their specific work environments, and the lack of evidence on the impact of the recommended systems. However, these limitations are a direct result of the decisions made during the survey design and development process, where priority was placed on developing a survey that would be rapid and easy to complete, hence the small number and simplicity of the survey questions. Finally, there are limitations in the types of analyses that can be conducted given the sample size achieved. For example, while it would be interesting to crossmatch countries' level of technologies to desired improvements, the overall sample size and unequal sample distribution of responses from various countries limits the meaningful insights that could be drawn from such analyses.

\section{Conclusions}

This study was aimed to identify the ways in which healthcare information and communication technologies can be improved to address challenges raised by the COVID-19 pandemic. Our results help to identify several important health information technologies, suggested by practicing health informatics experts internationally. These technologies were suggested as mechanisms to support professionals work to provide better care to patients during the COVID-19 pandemic. Specifically, the needs for improvement regarding health information technologies concern telehealth, advanced software to collect and analyze data, EHRs, remote work technologies, and clinical decision support tools. In addition, our results highlighted the need to improve interoperability, develop and implement intuitive user interfaces, and advocate for adoption of standards of care. The results of this study highlight the necessity for the health informatics community to work transdisciplinary to prioritize technology development based on the acute needs of healthcare systems and to emphasize end-user involvement throughout the development process to improve the usability of developed technologies. 


\section{Acknowledgment}

This study was supported by the Ryerson FCS COVID-19 Rapid Response Research Grant from Ryerson University, Toronto, Canada. Hans Moen acknowledges the Academy of Finland funding for providing the opportunity to contribute to this article.

\section{References}

1. Turale S, Meechamnan C, Kunaviktikul W. Challenging times: ethics, nursing and the COVID-19 pandemic. Int Nurs Rev 2020 Jun;67(2):164-7.

2. Ng K, Poon BH, Kiat Puar TH, Shan Quah JL, Loh WJ, Wong YJ, et al. COVID-19 and the Risk to Health Care Workers: A Case Report. Ann Intern Med 2020 Jun 2;172(11):766-7.

3. Gordon AL, Goodman C, Achterberg W, Barker RO, Burns E, Hanratty B, et al. Commentary: COVID in care homes-challenges and dilemmas in healthcare delivery. Age Ageing 2020 Aug 24:49(5):701-5.

4. Moazzami B, Razavi-Khorasani N, Dooghaie Moghadam A, Farokhi E, Rezaei N. COVID-19 and telemedicine: Immediate action required for maintaining healthcare providers well-being. J Clin Virol 2020 May;126:104345.

5. Zerbini G, Ebigbo A, Reicherts P, Kunz M, Messman H. Psychosocial burden of healthcare professionals in times of COVID-19 - a survey conducted at the University Hospital Augsburg. Ger Med Sci 2020 Jun 22;18:Doc05.

6. Arcadi P, Simonetti V, Ambrosca R, Cicolini G, Simeone S, Pucciarelli G, et al. Nursing during the COVID-19 outbreak: a phenomenological study. J Nurs Manag 2021 Jan 9.

7. Nagesh S, Chakraborty S. Saving the frontline health workforce amidst the COVID-19 crisis: Challenges and recommendations. J Glob Health 2020 Jun;10(1):010345.

8. Ranney ML, Griffeth V, Jha AK. Critical Supply Shortages - The Need for Ventilators and Personal Protective Equipment during the Covid-19 Pandemic. N Engl J Med 2020 Apr 30;382(18):e41.

9. Kang JY, Michels A, Lyu F, Wang S, Agbodo N, Freeman VL, et al. Rapidly measuring spatial accessibility of COVID-19 healthcare resources: a case study of Illinois, USA. Int J Health Geogr 2020 Sep 14;19(1):36.

10. Farrell TW, Francis L, Brown T, Ferrante LE, Widera E, Rhodes R, et al. Rationing Limited Healthcare Resources in the COVID-19 Era and Beyond: Ethical Considerations Regarding Older Adults. J Am Geriatr Soc 2020 Jun;68(6):1143-9.

11. Boškoski I, Gallo C, Wallace MB, Costamagna G. COVID-19 pandemic and personal protective equipment shortage: protective efficacy comparing masks and scientific methods for respirator reuse. Gastrointest Endosc 2020 Sep;92(3):519-23.

12. The Lancet. COVID-19: protecting health-care workers. Lancet 2020 Mar 21;395(10228):922.

13. Scott BK, Miller GT, Fonda SJ, Yeaw RE, Gaudaen
JC, Pavliscsak HH, et al. Advanced Digital Health Technologies for COVID-19 and Future Emergencies. Telemed JE Health 2020 Oct;26(10):1226-33.

14. Ye J. The Role of Health Technology and Informatics in a Global Public Health Emergency: Practices and Implications From the COVID-19 Pandemic. JMIR Med Inform 2020 Jul 14;8(7):e19866.

15. Vaishya R, Javaid M, Khan IH, Haleem A. Artificial Intelligence (AI) applications for COVID-19 pandemic. Diabetes Metab Syndr 2020 JulAug;14(4):337-9.

16. James HM, Papoutsi C, Wherton J, Greenhalgh T, Shaw SE. Spread, Scale-up, and Sustainability of Video Consulting in Health Care: Systematic Review and Synthesis Guided by the NASSS Framework. J Med Internet Res 2021 Jan 26;23(1):e23775.

17. Bokolo AJ. Exploring the adoption of telemedicine and virtual software for care of outpatients during and after COVID-19 pandemic. Ir J Med Sci 2021 Feb;190(1):1-10

18. Li Z, Chen Q, Feng L, Rodewald L, Xia Y, Yu H, et al; China CDC COVID-19 Emergency Response Strategy Team. Active case finding with case management: the key to tackling the COVID-19 pandemic. Lancet $2020 \mathrm{Jul}$ 4;396(10243):63-70.

19. Cheng W, Hao C. Case-Initiated COVID-19 Contact Tracing Using Anonymous Notifications. JMIR Mhealth Uhealth 2020 Jun 22;8(6):e20369.

20. Budd J, Miller BS, Manning EM, Lampos V, Zhuang M, Edelstein M, et al. Digital technologies in the public-health response to COVID-19. Nat Med 2020 Aug;26(8):1183-92.

21. Khan H, Kushwah KK, Singh S, Urkude H, Maurya MR, Sadasivuni KK. Smart technologies driven approaches to tackle COVID-19 pandemic: a review. 3 Biotech 2021 Feb;11(2):50.

22. Clipper B. The Influence of the COVID-19 Pandemic on Technology: Adoption in Health Care. Nurse Lead 2020 Oct;18(5):500-3.

23. Uohara MY, Weinstein JN, Rhew DC. The Essential Role of Technology in the Public Health Battle Against COVID-19. Popul Health Manag 2020 Oct;23(5):361-7.

24. Syeda HB, Syed M, Sexton KW, Syed S, Begum S, Syed F, et al. Role of Machine Learning Techniques to Tackle the COVID-19 Crisis: Systematic Review. JMIR Med Inform 2021 Jan 11;9(1):e23811.

25. HL7 FHIR Foundation. Welcome to the HL7 FHIR Foundation [Internet]. 2021 [cited January 30, 2021]. Available from: http://www.fhir.org/

26. openEHR Foundation. What is openEHR? [Internet]. 2021 [cited January 30, 2021]. Available from https://openehr.org/

27. SNOMED International. SNOMED International determines global standards for health terms, an essential part of improving the health of humankind [Internet]. 2021 [cited January 30, 2021]. Available from: https://www.snomed.org/

28. Schulz S, Stegwee R, Chronaki C. Standards in Healthcare Data. In: Kubben P, Dumontier M, Dekker A, editors. Fundamentals of Clinical Data Science. Cham: Springer; 2019. p. 19-36.

29. Marcilly R, Schiro J, Beuscart-Zéphir MC, Magrabi F. Building Usability Knowledge for Health Information Technology: A Usability-Oriented Analysis of Incident Reports. Appl Clin Inform 2019 May;10(3):395-408.
30. Carayon P, Xie A, Kianfar S. Human factors and ergonomics as a patient safety practice. BMJ Qual Saf 2014 Mar;23(3):196-205.

31. Avanesova AA, Shamliyan TA. Worldwide implementation of telemedicine programs in association with research performance and health policy. Health Policy Technol 2019 Jun 1;8(2):179-91.

32. Feild L, Pruchno RA, Bewley J, Lemay EP Jr, Levinsky NG. Using probability vs. nonprobability sampling to identify hard-to-access participants for health-related research: costs and contrasts. J Aging Health 2006 Aug; 18(4):565-83.

33. Etikan I, Bala K. Sampling and sampling methods. Biom Biostat Int J 2017;5(6):00149.

34. Dillman DA, Smyth JD, Christian LM. Internet, phone, mail, and mixed-mode surveys: the tailored design method. N.Y.: John Wiley \& Sons; 2014.

35. Dillman DA. Mail and Internet surveys: The tailored design method--2007 Update with new Internet, visual, and mixed-mode guide. N.Y.: John Wiley \& Sons; 2011.

36. Reja U, Manfreda KL, Hlebec V, Vehovar V. Open-ended vs. close-ended questions in web questionnaires. Developments in applied statistics 2003 Aug;19(1):159-77.

37. Elo S, Kyngäs H. The qualitative content analysis process. J Adv Nurs 2008 Apr;62(1):107-15.

38. Atreja A, Gordon SM, Pollock DA, Olmsted RN, Brennan PJ; Healthcare Infection Control Practices Advisory Committee. Opportunities and challenges in utilizing electronic health records for infection surveillance, prevention, and control. Am J Infect Control 2008 Apr;36(3 Suppl):S37-46.

39. Ohannessian R, Duong TA, Odone A. Global Telemedicine Implementation and Integration Within Health Systems to Fight the COVID-19 Pandemic: A Call to Action. JMIR Public Health Surveill 2020 Apr 2;6(2):e18810.

40. Lee D, Moy N, Tritter J, Paolucci F. The COVID-19 pandemic: Global health policy and technology responses in the making. Health Policy Technol 2020 Dec;9(4):397-8.

41. Fisk M, Livingstone A, Pit SW. Telehealth in the Context of COVID-19: Changing Perspectives in Australia, the United Kingdom, and the United States. J Med Internet Res 2020 Jun 9;22(6):e19264.

42. Atique S, Bautista JR, Block LJ, Lee JJ, Lozada-Perezmitre E, Nibber R, et al. A nursing informatics response to COVID-19: Perspectives from five regions of the world. J Adv Nurs 2020 Oct; 76(10):2462-8.

43. Han E, Tan MMJ, Turk E, Sridhar D, Leung GM, Shibuya K, et al. Lessons learnt from easing COVID-19 restrictions: an analysis of countries and regions in Asia Pacific and Europe. Lancet 2020 Nov 7;396(10261):1525-34.

44. Whitelaw S, Mamas MA, Topol E, Van Spall HGC. Applications of digital technology in COVID-19 pandemic planning and response. Lancet Digit Health 2020 Aug;2(8):e435-e440.

45. Monaghesh E, Hajizadeh A. The role of telehealth during COVID-19 outbreak: a systematic review based on current evidence. BMC Public Health 2020 Aug 1;20(1):1193.

46. Krausz M, Westenberg JN, Vigo D, Spence RT, Ramsey D. Emergency Response to COVID-19 in Canada: Platform Development and Implemen- 
tation for eHealth in Crisis Management. JMIR Public Health Surveill 2020 May 15;6(2):e18995.

47. Bauer DC, Metke-Jimenez A, Maurer-Stroh $\mathrm{S}$, Tiruvayipati S, Wilson LOW, Jain Y, et al. Interoperable medical data: the missing link for understanding COVID-19. Transbound Emerg Dis 2020 Oct 23

48. O'Reilly-Shah VN, Gentry KR, Van Cleve W, Kendale SM, Jabaley CS, Long DR. The COVID-19 Pandemic Highlights Shortcomings in US Health Care Informatics Infrastructure: A Call to Action. Anesth Analg 2020 Aug;131(2):340-4.

49. Mostashari F, McClellan MB. White paper: Data Interoperability and Exchange to Support COVID-19 Containment [Internet]. 2020 [cited January 30, 2021]. Available from: https://healthpolicy.duke.edu/publications/data-interoperability-and-exchange-support-covid-19-containment

50. Ratwani RM, Reider J, Singh H. A Decade of Health Information Technology Usability Challenges and the Path Forward. JAMA 2019 Feb 26;321(8):743-4

51. Topaz M, Ronquillo C, Peltonen LM, Pruinelli L, Sarmiento RF, Badger MK, et al. Nurse Informaticians Report Low Satisfaction and Multi-level
Concerns with Electronic Health Records: Results from an International Survey. AMIA Annu Symp Proc 2017 Feb 10;2016:2016-25.

52. Schrager JD, Schuler K, Isakov AP, Wright DW, Yaffee AQ, Jacobson KL, et al. Development and Usability Testing of a Web-based COVID-19 Self-triage Platform. West J Emerg Med 2020 Aug 19;21(5):1054-8.

53. Pal D, Vanijja V. Perceived usability evaluation of Microsoft Teams as an online learning platform during COVID-19 using system usability scale and technology acceptance model in India. Child Youth Serv Rev 2020 Dec;119:105535.

54. Lian W, Wen L, Zhou Q, Zhu W, Duan W, Xiao X, et al. Digital Health Technologies Respond to the COVID-19 Pandemic In a Tertiary Hospital in China: Development and Usability Study. J Med Internet Res 2020 Nov 24;22(11):e24505.

55. Garcia M, Lipskiy N, Tyson J, Watkins R, Esser ES, Kinley T. Centers for Disease Control and Prevention 2019 novel coronavirus disease (COVID-19) information management: addressing national health-care and public health needs for standardized data definitions and codified vocabulary for data exchange. J Am Med Inform Assoc $2020 \mathrm{Jul}$
1;27(9):1476-87.

56. Dong X, Li J, Soysal E, Bian J, DuVall SL, Hanchrow Eet al. COVID-19 TestNorm: A tool to normalize COVID-19 testing names to LOINC codes. JAm Med Inform Assoc 2020 Jul 1;27(9):1437-42.

57. Sass J, Bartschke A, Lehne M, Essenwanger A, Rinaldi E, Rudolph S, et al. The German Corona Consensus Dataset (GECCO): a standardized dataset for COVID-19 research in university medicine and beyond. BMC Med Inform Decis Mak 2020 Dec 21;20(1):341.

58. Bakken S. Informatics impact requires effective, scalable tools and standards-based infrastructure. J Am Med Inform Assoc 2020 Jul 1;27(9):1341-2.

\section{Correspondence to:}

Laura-Maria Peltonen

Department of Nursing Science

20014 University of Turku

Finland

Tel.: + 358407222616

E-mail: laura-maria.peltonen@utu.fi 